RU Некоторые лексические закономерности переноса ударения на предлог в сочетаниях «предлог плюс существительное»

\begin{abstract}
Алтайская Е. М.
Аннотация. Статья посвящена лексическим факторам переноса ударения с имен существительных на предлоги в современном русском литературном языке. Цель исследования - определить условия, способствующие или препятствющие акцентированию служебных лексем в живой звучащей речи. Научная новизна состоит в том, что впервые выполнено комплексное социолингвистическое исследование акцентирования сочетаний «предлог плюс существительное» и сопоставлены кодифицированные и узуальные нормы акцентирования данных сочетаний. В результате исследования определены и подробно описаны языковые и социолингвистические факторы, влияющие на перенос ударения, и выявлены тенденции развития изучаемых норм.
\end{abstract}

\title{
Some Lexical Patterns of Stress Shift to a Preposition in Prepositional Phrases "Preposition + Noun"
}

\begin{abstract}
Altayskaya E. M.
Abstract. The paper addresses lexical factors of stress shift from nouns to prepositions in the modern Russian literary language. The purpose of the study is to determine the conditions that promote or hinder accentuation of functional lexemes in live spoken speech. Scientific novelty of the research lies in the fact that the author for the first time conducts a comprehensive sociolinguistic study on accentuation of prepositional phrases "preposition + noun" and compares codified and usual norms of accentuation of these phrases. As a result of the research, the linguistic and sociolinguistic factors that affect stress shift have been determined and described in detail and trends in the development of the considered norms have been identified.
\end{abstract}

\section{Введение}

Как известно, русское словесное ударение выделяет один из слогов неодносложного слова (Большая российская энциклопедия, 2016). Однако далеко не каждое слово в речи имеет ударение. Служебные слова - односложные союзы, частицы и предлоги - как правило, ударения лишены и примыкают к словам знаменательным, составляя вместе с ними одно фонетическое слово: по телефо́ну, на у́лице, на ле́кции. В некоторых случаях происходит обратное (Касаткин, 1995; 2003; 2006; Розенталь, Джанджакова, Кабанова, 2015). Ударение «переходит» со знаменательного слова на служебное: взять ребенка на́ руки, идти по́д руку, бывать на́ людях. Данный процесс на сегодня системно не изучен, нет и системного описания «младшей» произносительной нормы в данном аспекте. Есть мнение, что с течением времени явление исчезнет из языка, поскольку язык стремится к унификации. Тенденция к отказу от переноса ударения особенно ярко проявилась в XX столетии (Касаткина, 2001). Однако в ряде сочетаний напредложное ударение остается предпочтительным и даже единственным вариантом произношения. Поэтому важно понять, чем обусловлен данный феномен и действительно ли он является исчезающим.

Актуальность темы исследования вызвана необходимостью изучить узуальные нормы современной живой звучащей речи и сопоставить их с кодифицированными нормами. Сравнение данных, полученных в ходе изучения спонтанной речи, с данными лексикографических источников служит основой для сопоставительного анализа «старшей» и «младшей» норм произношения. Такой анализ необходим, чтобы выявить внутренние и внешние причины наблюдаемых акцентологических изменений.

Для достижения поставленной цели важно решить следующие задачи: во-первых, проанализировать специальную научную литературу по изучаемому вопросу и определить ключевые подходы к его решению; вовторых, провести анализ данных словарей в рассматриваемом аспекте и найти закономерности, лежащие в основе кодификации норм; в-третьих, собрать представительный корпус фактических данных о месте ударения 
в сочетаниях «предлог плюс существительное»; в-четвертых, определить и описать систему языковых и социолингвистических факторов, способных влиять на акцентирование в изучаемых сочетаниях; в-пятых, определить тенденции развития акцентологических норм на рассматриваемом участке системы произношения и выявить причины и следствия происходящих изменений.

Для того чтобы успешно решить поставленные задачи, были применены следующие методы исследования: анализ письменных источников, логические методы (анализ, синтез, индукция и сравнение) для определения причинно-следственных связей, метод направленного наблюдения над звучащей речью носителей языка и анализ данных, полученных в ходе такого наблюдения (в том числе диктофонных записей речи участников эксперимента и др.).

Данные собирались в процессе сплошной выборки анализируемых фактов из лексикографических источников, а также различных кинофильмов, теле- и радиопередач за период с 1940-х по 2010-е гг. и в ходе направленного наблюдения за спонтанной звучащей речью носителей русского литературного произношения.

Исследование начато в 2006 году, однако сбор представительного корпуса примеров продолжается и сегодня. Решение поставленных задач стало возможным благодаря теоретической базе, которая включает в себя труды Н. А. Еськовой (1994), А. А. Зализняка (2003), М. Л. Каленчук, Л. Л. Касаткина, Р. Ф. Касаткиной (2012; Касаткин, 1995; 2003; 2006; Касаткина, 2001) и Н. Юкая (Ukiah, 1998). Н. Юкая, в частности, провел эксперимент, заключавшийся в прочтении 21 диктором специально составленного текста, в котором исследуемые сочетания были замаскированы другими, также неоднозначными в плане акцентирования. Н. А. Еськова обратила внимание на роль контекста при постановке ударения в изучаемых сочетаниях. А. А. Зализняк формулирует несколько правил переноса ударения, связанных со значениями предлогов. В Большом орфоэпическом словаре русского языка М. Л. Каленчук, Л. Л. Касаткина, Р. Ф. Касаткиной (2012) впервые отмечается перенос ударения как особенность «старшей» нормы произношения, а также приводятся сочетания, где напредложное ударение предпочтительно или обязательно. Р. Ф. Касаткина (2001) также обращает внимание на роль языковой памяти и литературных источников для изучаемого явления.

Материал исследования - данные анализа лексикографических источников (ряда орфоэпических и толковых словарей XX-XXI веков). Также изучены результаты направленного наблюдения за спонтанной живой звучащей речью носителей языка. К началу 2021 г. получено 14165 примеров от 2067 информантов в возрасте от 6 до 85 лет.

Практическая значимость исследования состоит в возможности применять полученные данные в практике преподавания современного русского языка, русского языка как иностранного (ведь фонетический аспект исключительно важен для иностранных студентов (Шутова, Орехова, 2018)), русского языка и культуры речи, при подготовке учебных пособий по данным дисциплинам, а также при составлении различных словарей, в особенности словарей орфоэпических.

\section{Основная часть}

Следует вновь обратить внимание на то, что чем употребительнее в повседневной речи сочетание «ударного» предлога и «безударной» словоформы существительного, тем вероятнее напредложное ударение (Алтайская, 2007).

Данная тенденция подтверждается и в ходе анализа русской классической поэзии: «Стал на́ воз, видим крестится на все четыре стороны» (Некрасов, 1952), «Молчалин на́ лошадь садился», «Он о́б землю и прямо в темя» (Грибоедов, 1986), «И днем, и ночью кот ученый все ходит по́ цепи кругом» (Пушкин, 1995), «Дело по́д вечер, зимой, и морозец знатный» (Некрасов, 1952). Подобные варианты акцентирования сегодня рассматриваются как устаревшие в силу меньшего употребления названных сочетаний в спонтанной звучащей речи.

Среди важных условий переноса ударения с имени существительного на предлог следует отметить и смыслоразличительную функцию переноса ударения (Алтайская, 2021; Еськова, 1994): отдыхать за́ городом и повернуть за го́родом; путешествовать по ми́ру и пустить по́ миру; и, как отметил один из участников исследования, «эксперимент проводится на лю́дях, а не на́ людях».

Таким образом, следует предположить важность влияния лексических факторов на перенос ударения с имен существительных на предлоги. Поэтому представляется интересным составить конечные списки «безударных» существительных на материале анализа данных словарей и по итогам наблюдения за спонтанной речью носителей языка. При составлении таких списков появляется возможность подробнее рассмотреть лексические особенности изучаемого явления. Здесь важно развить и направление, намеченное Н. Юкая (Ukiah, 1998), а именно разработку лексико-семантической классификации тех имен существительных, которые в некоторых своих словоформах способны отдавать ударение («безударные» имена существительные называются также энклиноменами).

Как уже отмечено, одним из этапов настоящего исследования стал анализ данных словарей, составленных в XX-XXI веках. Автором изучались как орфоэпические, так и толковые словари, где в ряде словарных статей отдельно отмечаются сочетания интересующих имен существительных с ударными предлогами (Аванесов, Ожегов, 1959; Агеенко, Зарва, 1984; Борунова, Воронцова, Еськова, 1983; Еськова, 1994; Зализняк, 2003; Каленчук, Касаткин, Касаткина, 2012; Ожегов, 1973; Ожегов, Шведова, 1992; Орфоэпический словарь..., 2015; Резниченко, 2008; Штудинер, 2016). В результате был составлен общий список знаменательных лексем, в некоторых своих словоформах способных отдавать ударение тем или иным служебным словам. Приведем данный перечень в алфавитном порядке: берег, бок, борт; верста, весть, ветер, вечер, вид, вода, воз, волос, ворот; 
глаз, год, голова, гора, город; двор, день, дом, дух, душа; земля, зима, зуб; кол, кон, коса, кровь, крик; лед, лес, лето, лоб, луг, люди; мир, море, мост; небо, нога, нос, ночь; плечи, пол, поле, полдень, полночь, пояс; река, род, рука; сад, свет, сердие, слово, смерть, смех, снег, спина, спор, стена, стол, сторона; толк; угол, ус, ухо; фиг; цепь; час; щека. Как видно из приведенного перечня, изучаемое явление затрагивает 72 имени существительных. Среди них выделяются 19 лексем, способных к переносу ударения только во фразеологических сочетаниях: весть, глаз, дух, душа, зуб, кол, кон, крик, люди, мир, полдень, полночь, пояс, род, свет, слово, спор, ус, час.

Отмеченные 72 энклиномена можно распределить по нескольким лексико-семантическим группам.

Первая и самая обширная - лексемы, обозначающие части тела и другие особенности внешнего строения живого организма (человека или животного). K данной группе следует отнести следующие имена существительные: бок, волос, глаз, голова, зуб, коса, кровь, лоб, нога, нос, плечо, рука, спина, ус, ухо, щека. Любопытно, что наибольшее число перечисленных слов относятся к голове и лицу.

Лексемы, представляющие собой обиходные названия внешних, видимых частей организма, активно отдают ударение предлогам. Перенос ударения происходит как в свободных сочетаниях, где названные существительные сохраняют свое буквальное значение (возьмемся за́ руки, друзья; сидеть нога на́ ногу; Вася на́ голову выше Пети), так и в различных фразеологизмах, характеризующих, как правило, человеческие качества и житейские ситуации: как врач он на́ голову выше своих коллег; девочка влюбилась по́ уши; поставить на́ ноги (вылечить или сделать материально самостоятельным, способным о себе заботиться, независимым от других лиц); встать на́ ноги (стать материально независимым и способным о себе заботиться); рука о́б руку (дружно, совместно) и мн. др. Некоторые устойчивые сочетания, например вести по́д руку или говорить на́ ухо, сохраняют буквальное значение. Значительная часть фразеологизмов данной группы обозначает человеческие качества, состояния и их проявления в действиях: схватиться за́ голову, сесть на́ голову, скор на́ руку, тугой на́ ухо.

К следующей лексико-семантической группе относятся имена существительные, обозначающие время. В сочетаниях с предлогами в некоторых своих словоформах становятся безударными лексемы: вечер, год, день, зима, лето, ночь, полдень, полночь, свет (в значении «рассвет», в устаревшем сочетании «до свету»), час. Например, «вот и стали мы на́ год взрослей...» или «за́ день мы устали очень». Все перечисленные имена существительные обозначают только те единицы измерения времени, которыми человек активно пользуется в повседневной жизни.

Данную лексико-семантическую группу можно условно разделить на две подгруппы. К первой подгруппе относятся наименования тех или иных частей суточного цикла: вечер, день, ночь, полдень, полночь, свет, час. Ко второй подгруппе следует отнести лексемы, обозначающие части цикла годового: год, зима, лето. Слово утро, которое сегодня уже не отдает ударение предлогам, в древнерусском языке относилось к разряду энклиноменов (т.е. не имело фонологически ударного слога). Следы его «безударности» сегодня видны в производной от него лексеме завтра (ранее это слово произносилось и писалось «заутра», что можно увидеть и в современных церковнославянских текстах). Способность отдавать ударение предлогам, вероятно, теряет и существительное вечер. Некрасовское «дело по́д вечер» современный носитель языка воспринимает скорее как дополнительный устаревший вариант произношения. Следует обратить внимание на то, что сочетания с «безударными» существительными данной группы употребляются, как правило, для обозначения циклического, а не линейного времени. Однако есть исключения: год о́m году - с каждым следующим годом; с году на́ год - с одного года на следующий; и́з году в год - каждый год; и́зо дня в день - каждый день; со дня на́ день - с одного дня на следующий. Лексема день в рассмотренных сочетаниях приобретает значение «сутки», а не «светлое время суток».

К третьей лексико-семантической группе «безударных» имен существительных относятся лексемы, обозначающие природные объекты и явления: берег, ветер, вода, лед, река, снег, море, гора, земля, лес, луг, небо, поле, сад. Носителям языка известны такие сочетания, как поехать на́ море отдохнуть, спустить шлюпки на́ воду, держать нос по́ ветру, гулять по́ лесу и т.д. Некоторые варианты с ударением на предлоге в словарях отмечены как дополнительные устаревшие, например на́ землю или по́ саду. В данной лексикосемантической группе также можно выделить подгруппы лексем с общими компонентами значения. Например, «водное пространство» (берег, вода, река, море), «совокупность растений» (лес, луг, поле, сад), «погодные явления» (ветер, лед, снег). Интересно, что существительные-энклиномены называют лишь те водные объекты, которые возникли естественным путем, а не созданы человеком (пруд и т.п.). Кроме того, отдавать ударение предлогам способны только имена существительные, обозначающие «средние» водные объекты, привычные для носителя языка. Лексемы, указывающие на маленькие (например, ручей или лужа), особо крупные (океан) или нетипичные водные объекты (пролив, залив), изучаемое явление не затрагивает (данная закономерность справедлива и для группы энклиноменов, характеризующих время, - в нее входят только наименования «средних» и наиболее типичных для повседневной жизни временных отрезков).

Следует отметить и то, что ударение предлогам отдают имена существительные - родовые названия, гиперонимы природных явлений и объектов. Снег - но не наст или пороша, гора - но не сопка или холм. Лес - но не бор или роща.

Четвертая лексико-семантическая группа изучаемых имен существительных обозначает помещение и его части: дом (в значении «семейное жилище»), пол, стена, угол. Например, повернуть за́ угол, выйти úз дому, уронить на́ пол, лезть на́ стену, задание на́ дом. Возможно, бывшим энклиноменом является слово верх, также способное обозначать часть здания. Об этом свидетельствуют наречия до́верху и по́верху с ударением на приставке. В речи старших носителей языка и ряде стихотворных текстов встречается акцентирование приставки в наречии наверх. 
Пятая лексико-семантическая группа содержит наименования некоторых объектов созданного человеком пространства. Некоторые словоформы имен существительных верста (только в дополнительных устаревших вариантах произношения), город, двор, мост способны произноситься без ударения в сочетаниях с рядом предлогов. Лексема верста стала историзмом и в повседневной бытовой речи более не употребляется, т.к. для измерений применяются метрические меры длины. Поэтому данное слово уходит из разряда энклиноменов. Однако такие сочетания, как уехать за́ город или бегать по́ двору, остаются распространенными в современной спонтанной речи.

Шестая лексико-семантическая группа содержит обиходные наименования социума и некоторых его частей: люди, мир, свет, сторона. Все эти сочетания - фразеологические: показаться на́ люди, пойти по́ миру, сживать со́ свету, ходить на́ сторону. Семантика сочетаний на́ люди, на́ людях близка семантике выражений в свет (выйти), в обществе (бывать). Энклиномен сторона называет ту часть социума, которая чужда для говорящего или слушающего.

Седьмая лексико-семантическая группа объединяет имена существительные с компонентами значения «речь, информация, проявления эмоций»: весть, крик, слово, смех (в основном в значении насмешки), сnор. Ряд ученых предполагает, что энклиномен спор является новым и ранее ударение предлогам не отдавал. Сочетания, допускающие акцентирование служебных лексем, также являются фразеологическими: пропавший бе́з вести, на́ крик кричать (перенос ударения происходит только в дополнительных устаревших вариантах), поверить на́ слово, ловить на́ слове, поднять на́ смех, сделать на́ спор.

Восьмая группа «безударных» имен существительных обозначает артефакты, вещи и предметы: борт, воз, ворот, кол, пояс, стол, цепь. Такие сочетания, как выбросить за́ борт, посадить на́ кол, кулаком по́ столу, часто употребляются в современной живой звучащей речи. Фразеологизм за́ пояс заткнуть (превзойти в чемлибо) в настоящее время обычно произносится с ударением на знаменательной лексеме. Фразеологизм по́ ворот при наблюдении за спонтанной речью носителей языка зафиксировать не удалось. В данном значении произносится другое фразеологическое сочетание с ударным предлогом - по́ уши.

Девятая группа энклиноменов характеризует внутренний мир человека. Существительные дух, душа, сердие отдают ударение предлогам в ряде фразеологических сочетаний: на́ дух не переносить, за́ душу берет, бальзам на́ душу, легко на́ сердце, пришелся по́ сердцу.

Семантика энклиноменов душа и сердце, имеющих общие компоненты значения, имеет следующие различия. Душа воспринимается не только в контексте атеистического восприятия (многие проанализированные словари были составлены в советскую эпоху) - как внутренний мир человека, но и в первоначальном значении - в контексте представлений о Боге и вере в Бога. В выражении бальзам на́ дущу она неожиданно воспринимается как нечто вещественное и совпадает в этом компоненте значения с лексемой сердие.

Сердце же как энклиномен - обозначение внутреннего мира человека, частично сохраняющее первоначальную семантику жизненно важного органа. Фразеологические сочетания с этим энклиноменом обозначают одновременно и эмоции, и реальные физические ощущения в различных ситуациях.

Еще несколько имен существительных сложно отнести к какой-либо лексико-семантической группе: вид, кон, род, смерть, толк, фиг. Перечисленные лексемы активно отдают ударение предлогам во фразеологических сочетаниях, например, скрыться и́з виду, поставить на́ кон, столько-то лет о́т роду, бороться не на жизнь, a на́ смерть, все бе́з толку. Сочетания с просторечной лексемой фиг (указанной, как ни странно, в некоторых орфоэпических словарях позднего советского периода) в течение времени исследования стремительно превращаются в наречия: в 2016-2020 гг. в личной переписке носителей языка и на интернет-страницах слитное написание на́фuг, пóфuг встречается значительно чаще, чем в 2006 году, когда стартовало исследование. Данный языковой процесс затронул и другие сочетания безударных словоформ имен существительных с ударными предлогами: например, повернуть на́бок и он лег на́ бок и уснул.

Интересно и то, что в произношении сочетаний ударных предлогов с формами просторечной лексемы фиг не зафиксировано ни одного варианта без переноса ударения на служебное слово. Отсутствие зафиксированных вариантов произношения с ударением на предлог характеризует и такие сочетания, как пропал бе́з вести, сделать на́ спор, посадить на́ кол, поставить на́ кон, за́ полночь и др.

По материалам анализа данных словарей и по результатам предпринятой лексико-семантической классификации возможно понять, какие объекты, качества, действия, явления и состояния чаще всего упоминались в повседневной спонтанной речи носителей языка в середине XX столетия. В первую очередь, это живые существа - и человек, и животные (причем не только в аспекте внешнего строения и здоровья, но и в аспекте чувств, эмоций, свойств характера). Во-вторых, это различная деятельность человека: его социальные взаимодействия (в особенности вербальная коммуникация с выраженным оценочным компонентом), труд, в том числе домашний, повседневный. Некоторые сочетания с переносом ударения на предлог характеризуют деятельность с точки зрения полученной пользы или выгоды (например, на́ руку, бе́з толку). В-третьих, это время, в основном в аспекте его природных циклов - суточного и годового. Интересно, что сочетания, характеризующие отклонения деятельности человека от природного режима (на́ ночь глядя, за́ полночь, с утра до́ ночи), часто имеют негативный оценочный компонент. В-четвертых, это природа, природные объекты и явления. В сочетаниях с переносом ударения на предлог они чаще рассматриваются как пространственные ориентиры. B-пятых, пространство и вещи, созданные человеком.

Таким образом, подтверждается вывод, что способность существительного к переносу ударения зависит от привычности для носителя языка понятия, обозначаемого данной лексемой. При этом лексема не должна 
обозначать что-либо предельно конкретное, уникальное или находящееся в центре внимания в данной ситуации. Перенос ударения происходит значительно чаще, если речь идет о некоторой совокупности предметов (понятий) или предмете (понятии), не находящемся в центре внимания, но, безусловно, важном для говорящего и/или слушающего.

Изменение конкретно-исторической обстановки и мировосприятия носителя языка влечет изменение состава энклиноменов. Человек реже сталкивается с какими-либо явлениями, выходят из употребления те или иные вещи - и жизненные реалии переходят из разряда повседневных в разряд необычных (ср. за́ версту или nó ворот). Как следствие, сокращается употребление слов, которые их обозначают - и с течением времени вариант акцентирования с переносом ударения становится менее предпочтительным или устаревшим (Алтайская, 2007; 2021). Возможен и другой вариант, когда фразеологизм с ударным предлогом исчезает из повседневной речи или употребляется значительно реже, а на его место приходит другой с тем же значением. Носитель языка может сказать как видно за версту с ударением на существительном, так и за километр видно, а вместо по ворот в грязи скорее всего скажет по́ уши в грязи.

При этом важно изменение не только жизненных реалий, но и отношения к ним. Если в социуме становится принятым обращать меньшее внимание на какие-либо вещи или явления - это также может приводить к отказу от ударения на предлог.

Данные предположения, сделанные на основе анализа лексикографических источников, подтвердились и в процессе наблюдения за речью информантов, как знакомых автору, так и случайно им встреченных, а также за речью участников современных теле- и радиопередач.

Список лексем, наиболее активно отдающих ударение предлогам в современной живой звучащей речи, значительно меньше предложенного словарями. Отмечено 34 «безударных» имен существительных: весть, волос, вода; год, голова, город; день, дом, дух, душа; зима, зуб; кол, кон, коса; лес, лоб, люди; мир; нога, нос, ночь; пол, полночь; род, рука; свет (в значении «мир»), сердце, слово, спина, спор; ухо; час; фиг.

15 из этих лексем способны отдавать ударение только во фразеологизмах: весть; дух, душа; зуб; кол, кон; люди; мир; род; свет (в значении «мир»), сердце, слово, спор; час; фиг.

Краткость приведенного перечня, однако, не означает, что способность отдавать ударение предлогу утратили не указанные в нем «словарные» лексемы-энклиномены. Произношение, например, сочетаний на лето или на море с ударением на предлоге остается нормативным вариантом произношения (при этом следует отметить, что отдых в течение всего лета или поездка на отдых к морю сегодня воспринимаются скорее как исключительное событие, а не как часть повседневности). А такое сочетание, как за полдень, в спонтанной речи носителей языка зафиксировать не удалось (поэтому проверить его произношение не представляется возможным).

Наименьшие изменения претерпели семантические группы, представляющие особенности внешнего строения живого организма и обозначающие отрезки временных циклов. Так, в лексико-семантической группе существительных, обозначающих особенности внешнего строения организма живого существа, активными энклиноменами остались волос, голова, коса, лоб, нога, нос, рука, спина, ухо, щека. У лексем, обозначающих время, в современной живой звучащей речи перенос ударения на предлог чаще встречается в сочетаниях со словоформами лексем год, день, зима, ночь, полночь.

Следует отметить, что несколько реже стали отдавать ударение предлогу лексемы, представляющие части лица. А большинство сочетаний энклиноменов первой лексико-семантической группы с ударными предлогами подразумевают какое-либо воздействие на объект - в основном одевание, прикосновение и нанесение удара (за́ руку, на́ голову, по́ уху и т.п.). Часть распространенных в современной речи сочетаний (например, больной на́ голову, хромой на́ ногу) обозначает физические и умственные недостатки, проблемы со здоровьем и самочувствием.

Значительно сократилось число сочетаний, обозначающих время - несмотря на активное употребление носителями языка сочетаний лексем год и день с ударными предлогами.

Многие зафиксированные сочетания с энклиноменами ночь и зима произнесены в таких контекстах, где эти части временного цикла оцениваются отрицательно, как представляющие опасность и требующие осторожности.

Третью, четвертую и пятую группы, выделенные по результатам анализа словарей, по данным наблюдения за спонтанной речью необходимо будет объединить. Общим компонентом значения для энклиноменов новой группы будет семантика пространства: вода, река, лес, город, дом, море, пол, поле, угол. Перенос ударения происходит в основном в тех сочетаниях и контекстах, где характеристики природного объекта не являются значимыми, а важен лишь компонент значения «передвижение».

Лексико-семантическую группу существительных, обозначающих внутренний мир человека: дух, душа, сердие, - изменения затронули не столь значительно. Однако больше стало примеров сохранения ударения на знаменательной лексеме сердце.

Перенос ударения активно происходит и в группе существительных с компонентами значения «речь, информация, выражение эмоций»: весть, смех, сnор. Более того, в ходе наблюдения не было зафиксировано постановки ударения на существительном во фразеологических сочетаниях пропал/пропавщий бе́з вести, на́ сnор. Единичные случаи отсутствия переноса ударения были отмечены в произношении сочетания поднять на́ смех, однако они являются скорее исключением. Часто отдают ударение предлогам и лексемы, обозначающие артефакты, вещи, предметы: борт, кол, стол, кон, цепь.

В качестве абсолютного энклиномена можно рассматривать не только лексемы весть и спор, но и лексему фиг. Однако распространенность ее в речи носителей языка вызывает опасения, равно как и та роль, в которой 
употребляются сочетания ударных предлогов с данным именем существительным. Некоторые из них выступают как просторечные синонимы местоименных наречий «зачем» и «незачем», то есть приобретают одну из центральных ролей в предложении. Увеличилось также число тяготеющих к просторечию фразеологизмов.

\section{Заключение}

Результаты проведенного исследования позволили прийти к следующим выводам:

1) По итогам анализа данных словарей и данных наблюдения за живой звучащей речью носителей языка видно, что ключевой фактор переноса ударения на предлог - частота употребления тех или иных сочетаний «предлог плюс существительное» в спонтанной речи. При этом лексикографические источники отражают положение дел в более ранние периоды.

2) Среди факторов, влияющих на акцентирование изучаемых сочетаний, определяющими являются лексические закономерности. Особенно важна семантика «безударных» существительных. И по данным анализа словарей, и по данным наблюдения отдавать ударение предлогам способны те лексемы, которые обозначают: особенности внешнего строения живого организма; отрезки временных циклов; природные объекты и явления; помещение и его части; объекты созданного человеком пространства; обиходные названия социума; элементы вербальной коммуникации и выражения эмоций; артефакты, вещи, предметы; внутренний мир человека (есть и несколько существительных, не относящихся ни к одной из названных лексикосемантических групп). Т.е. «безударные» существительные называют те реалии, с которыми человек чаще всего встречается в повседневной жизни.

3) Сравнение «словарного» и «речевого» списков лексем подтверждает, что перенос ударения в большей степени характерен для «старшей» нормы произношения. Однако и в «младшей» норме есть сочетания, где вариант с напредложным ударением - предпочтительный или единственный. Постепенный отказ от акцентирования предлогов в сочетании с некоторыми именами существительными реализуется только как тенденция и явно не является завершенным.

4) Анализ примеров, зафиксированных в ходе наблюдения, позволяет обнаружить, что значительное число случаев отказа от переноса ударения в современной речи обусловлено обеднением активного словарного запаса носителей языка, происходящим с 1990-х годов, а также изменениями жизненных реалий.

5) Перенос ударения на служебное слово по-прежнему воспринимается как нормативное, «правильное» произношение, даже когда данное явление не совпадает с рекомендациями орфоэпических словарей.

Перспективы дальнейшего исследования заключаются в необходимости пересмотра произносительных рекомендаций, формулирующих правила постановки ударения в сочетаниях предлогов с определенными именами существительными. Для достижения этой цели важно разработать специальное лексикографическое приложение, которое даст возможность представить изучаемую произносительную норму в динамике.

\section{Источники | References}

1. Аванесов Р. И., Ожегов С. И. Русское литературное произношение и ударение: словарь-справочник. М.: Гос. изд-во иностр. и нац. словарей, 1959.

2. Агеенко Ф. Л., Зарва М. В. Словарь ударений для работников радио и телевидения / под ред. Д. Э. Розенталя. Изд-е 5-е. М.: Русский язык, 1984.

3. Алтайская Е. М. Закономерности акцентирования сочетаний предлогов с существительными в современном русском литературном языке // Фонетика сегодня: мат. докладов и сообщений V Междунар. науч. конф. (г. Москва, 8-10 октября 2007 г.). М.: Институт русского языка им. В. В. Виноградова РАН, 2007.

4. Алтайская Е. М. Некоторые закономерности переноса ударения на предлог в сочетаниях «предлог плюс существительное» // Филологические науки. Вопросы теории и практики. 2021. Т. 14. Вып. 1.

5. Борунова С. Н., Воронцова В. Л., Еськова Н. А. Орфоэпический словарь русского языка: произношение, ударение, грамматические формы: около 63500 слов / под ред. Р. И. Аванесова. Изд-е 1-е. М.: Русский язык, 1983.

6. Грибоедов А. С. Избранное / сост., вступ. ст. и ком. А. Л. Гришунина; ил. Е. М. Борисовой. М.: Правда, 1986.

7. Еськова Н. А. Краткий словарь трудностей русского языка: грамматические формы. Ударение: около 12000 слов. М.: Русский язык, 1994.

8. Зализняк А. А. Грамматический словарь русского языка. Словоизменение. Изд-е 4-е, испр. и доп. М.: Русские словари, 2003.

9. Каленчук М. Л., Касаткин Л. Л., Касаткина Р. Ф. Большой орфоэпический словарь русского языка. М.: АСТПресс, 2012.

10. Касаткин Л. Л. Клитики // Касаткин Л. Л., Клобуков Е. В., Лекант П. Л. Краткий справочник по современному русскому языку / под ред. П. Л. Леканта. Изд-е 2-е, испр. и доп. М.: Высшая школа, 1995.

11. Касаткин Л. Л. Современный русский язык. Фонетика. М.: Академия, 2006.

12. Касаткин Л. Л. Фонетика современного русского литературного языка. М.: Изд-во Моск. ун-та, 2003.

13. Касаткина Р. Ф. Об изменениях в просодической системе русского литературного языка в последние десятилетия // Слово в тексте и в словаре: сб. ст. к семидесятилетию акад. Ю. Д. Апресяна / отв. ред. Л. Л. Иомдин, Л. П. Крысин. М.: Яз. рус. культуры, 2001. 
14. Некрасов Н. А. Избранные произведения. М: Московский рабочий, 1952.

15. Ожегов С. И. Словарь русского языка / под ред. Н. Ю. Шведовой. М.: Советская энциклопедия, 1973.

16. Ожегов С. И., Шведова Н. Ю. Толковый словарь русского языка. М.: Азъ, 1992.

17. Орфоэпический словарь русского языка. Произношение, ударение, грамматические формы: свыше 70000 слов / под ред. Н. А. Еськовой. Изд-е 10-е, испр. и доп. М.: АСТ, 2015.

18. Пушкин А. С. Полное собрание сочинений: в 17-ти т. М.: Воскресенье, 1995. Т. 6.

19. Резниченко И. Л. Словарь ударений русского языка. М.: АСТ-Пресс, 2008.

20. Розенталь Д. Э., Джанджакова Е. В., Кабанова Н. П. Справочник по правописанию, произношению, литературному редактированию. М.: Айрис-Пресс, 2015.

21. Большая российская энциклопедия: в 35-ти т. М., 2016. Т. 32. Телевизионная башня - Улан-Батор.

22. Штудинер М. А. Словарь трудностей русского языка для работников СМИ: ударение, произношение, грамматические формы. М.: Словари XXI века, 2016.

23. Шутова М. Н., Орехова И. А. Фонетический аспект в методике преподавания русского языка как иностранного // Вестник Российского университета дружбы народов. Серия «Русский и иностранные языки и методика их преподавания». 2018. № 3.

24. Ukiah N. Stress Retraction in Phrases of the Type na den', za sorok, ne byl in Modern Russian // Russian Linguistics. 1998. Vol. 22. № 3.

\section{Информация об авторах | Author information}

\section{RU Алтайская Екатерина Михайловна ${ }^{1}$}

${ }^{1}$ Московский государственный университет имени М. В. Ломоносова

EN Altayskaya Ekaterina Mikhaylovna ${ }^{1}$
${ }^{1}$ Lomonosov Moscow State University

${ }^{1}$ ekaterina.altayskaya@gmail.com

\section{Информация о статье | About this article}

Дата поступления рукописи (received): 06.12.2021; опубликовано (published): 31.01.2022.

Ключевые слова (keywords): перенос ударения; напредложное ударение; вариативность акцентирования; энклиномен; лексические факторы; stress shift; prepositional stress; variation of accentuation; enclinomen; lexical factors. 